\title{
Astrocitomas
}

\section{Uma revisão abrangente}

Mário Henrique Girão Faria, Régia Maria do Socorro Vidal do Patrocínio², Silvia Helena Barem Rabenhorst ${ }^{3}$

Faculdade de Medicina - Universidade Federal do Ceará, Brasil

\section{RESUMO}

A presente revisão aborda os atuais conceitos sobre a origem celular, a etiologia, a classificação e a graduação dos astrocitomas. Os achados neuropatológicos característicos dos diferentes tipos de neoplasias astrociticas são apresentados de acordo com o sistema adotado pela Organização Mundial da Saúde. Além disso, relata-se o presente estado da arte acerca da genética molecular desses tumores. Após descrever o perfil epidemiológico e os aspectos clínicos gerais, a situação atual do tratamento multidisciplinar e as novas perspectivas terapêuticas para os astrocitomas são comentadas.

\section{PALAVRAS-CHAVE}

Astrocitomas, genética molecular. Astrocitomas, histopatologia. Astrocitomas, terapia.

\section{ABSTRACT}

Astrocytomas - a comprehensive review

The present review summarizes the current concepts on the cell origin, the etiology, the classification and the graduation of the astrocytomas. We expose the characteristic neuropathological features of the different types of astrocytic tumours according to the World Health Organization system. In addition, we report on the present state of the art concerning the molecular genetics of these tumours. After describing the epidemiological profile and the general clinical aspects, the actual status of multidisciplinary treatment and the new therapeutic perspectives for the astrocytomas is explained.

\section{KEY WORDS}

Astrocytomas, histopathology. Astrocytomas, molecular genetics. Astrocytomas, therapy.

\section{Breve histórico e origem celular}

Os astrocitomas constituem o principal tipo histológico dentre os tumores primários do sistema nervoso central (SNC). O termo astrocitoma foi cunhado por Virchow ${ }^{45}$ para designar os tumores compostos predominantemente por astrócitos atípicos (núcleos aumentados, alongados ou hipercromáticos com citoplasmas escassos, poucos definidos), porém, só foi empregado definitivamente na classificação proposta por Bailey e Cushing, em $1926^{2}$ (Figura 1).

Os astrócitos fazem parte das células gliais - elementos celulares responsáveis pelo suporte tecidual, nutrição, equilíbrio iônico, metabolismo de neurotransmissores e defesa imunológica dos neurônios. Estas células são representadas, além dos astrócitos, pelos oligodendrócitos, pelos ependimócitos e pelas células da micróglia ${ }^{14}$.

Recentes evidências sugerem ainda que as células astrocíticas, nove vezes mais numerosas que os neurônios, comunicam-se entre si através de sinais químicos, formando uma rede independente e paralela à neuronal. Esta comunicação neurônio-glia influenciaria a formação de sinapses e indicaria quais conexões neuronais se fortaleceriam ou enfraqueceriam com o tempo - fatores determinantes na fisiologia do aprendizado e do armazenamento da memória duradoura ${ }^{13}$.

1 Mestre em Farmacologia; Pesquisador do Laboratório de Genética Molecular - LABGEM. 


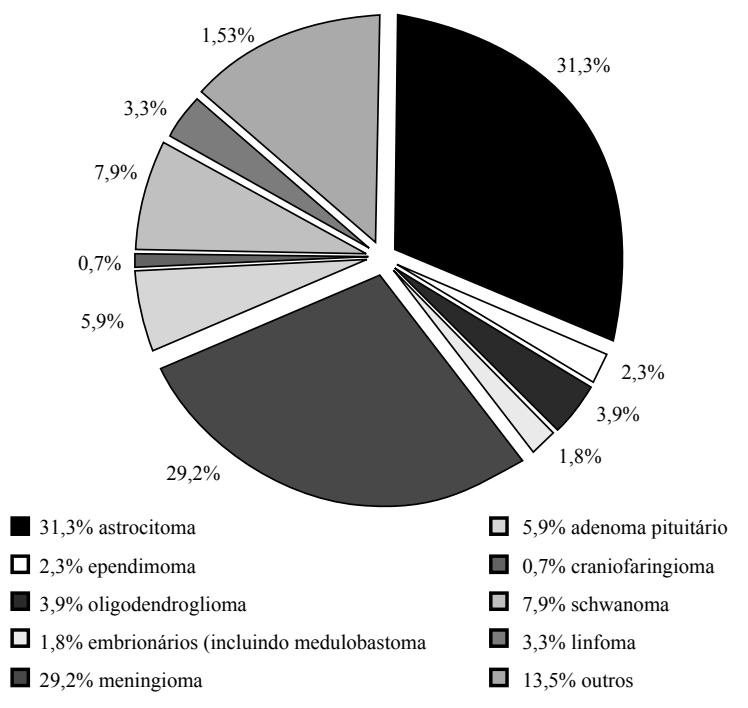

Figura 1 - Distribuição percentual dos tumores primários do SNC diagnosticados nos EUA, no período de 1997 a 2001, segundo a histopatologia $(n=58.907)$.

Fonte: CBTRUS (Central Brain Tumor Registry of the United States) ${ }^{5}$.

\section{Etiologia}

Apesar dos enormes esforços empreendidos na tentativa de se detectar correlações epidemiológicas entre exposição ocupacional, dieta e hábitos de vida dos pacientes e o surgimento dos tumores astrocíticos, nenhum destes fatores demonstrou significância estatística. De uma forma geral, a etiologia dos tumores originados no SNC ainda é pouco compreendida, à exceção do impacto das síndromes neoplásicas hereditárias (neurofibromatose, Li-Fraumeni, Turcot entre outras) ${ }^{35}$.

Inúmeros trabalhos sugerem a possibilidade de substâncias químicas (formaldeído, cloreto de vinil, solventes orgânicos), campos eletromagnéticos (telefones móveis, linhas de transmissão), alimentos (conservantes nitrosos), traumatismos cranianos, tabagismo, drogas (barbituratos) desencadearem a formação de tumores no SNC, entretanto, todos esses carecem de consistência epidemiológica e comprovação multicêntrica ${ }^{1}$.

$\mathrm{O}$ único fator ambiental inequivocamente associado ao maior risco de desenvolvimento dos astrocitomas, assim como de outros tumores do SNC, consiste na exposição à radiação (radiografias, radioterapia entre outras). Estudos experimentais apontam ainda alguns vírus como potenciais agentes etiológicos, todavia não se observa aumento da incidência de tumores astrocíticos em populações sabidamente mais expostas aos patógenos relacionados. Relata-se ainda que estados de imunossupressão (síndrome da imunodeficiência adquirida, pós-transplantados) predisporiam à manifestação dos astrocitomas, contudo essa correlação só foi comprovada no caso dos linfomas primários do $\mathrm{SNC}^{25}$.

\section{Classificação e graduação histopatológica}

Na recente classificação histopatológica da Organização Mundial da Saúde (OMS) para os tumores próprios do SNC, admite-se que as diversas apresentações histológicas dos astrocitomas possam ser divididas em diferentes graus de malignidade, variando de I a IV (Tabela 1) .

Essa graduação resulta do reconhecimento, através da análise histológica rotineira por microscopia óptica, de indicadores de anaplasia (atipia nuclear, pleomorfismo, atividade mitótica, hiperplasia endotelial e necrose) típicos de cada variante tumoral. Como regra geral, o grau tumoral é baseado nas áreas de maior atipia, assumindo que esta população de células é a que determina o curso da doença. Além de manifestar o comportamento biológico tumoral, permitindo inferências prognósticas, o acúmulo de achados anaplásicos parece refletir a progressão das alterações moleculares adquiridas durante o processo de transformação neoplásica ${ }^{22}$.

No esquema de graduação adotado pela OMS, a presença de atividade mitótica define os tumores de alto grau (III e IV). A presença de necrose tumoral, acompanhada ou não por hiperplasia endotelial, delimita o grau IV. A detecção unicamente de atipia citológica (pleomorfismo celular e/ou atipia nuclear) estabelece o grau II. Os tumores do grau I consistem em entidades distintas: além da ausência de anaplasia, têm sua gradação definida ainda por parâmetros clínicos (idade do paciente, localização tumoral, aspecto radiológico $)^{3}$.

\section{Caracterização dos astrocitomas}

\section{Astrocitomas grau I (OMS) - Astrocitoma pilocítico}

São tumores de crescimento lento, geralmente de origem cerebelar ( $>80 \%)$. Macroscopicamente, apresentam-se como massas bem delimitadas, na maioria das vezes císticas, sem infiltração dos tecidos subjacentes. Microscopicamente, são constituídos por células pilóides bipolares que se organizam em densa rede fibrilar, muitas vezes com microcistos de conteúdo mucinoso. A distribuição radial do tecido tumoral ao 


\begin{tabular}{|c|c|c|c|}
\hline \multicolumn{4}{|c|}{ Tabela 1} \\
\hline \multicolumn{4}{|c|}{ Tumores de origem neuroepitelial - representação parcial (tumores astrocíticos e correlatos) da classificação segundo a OMS } \\
\hline \multicolumn{2}{|c|}{ Tumores de origem neuroepitelial } & Código ICD-O / SNOMED ${ }^{1}$ & Comportamento biológico ${ }^{2}$ \\
\hline \multicolumn{4}{|c|}{ Tumores astrocíticos } \\
\hline Grau I & Astrocitoma pilocítico & 9421 & 1 \\
\hline \multirow[t]{4}{*}{ Grau II } & Astrocitoma difuso & 9400 & 3 \\
\hline & Astrocitoma fibrilar & 9420 & 3 \\
\hline & Astrocitoma protoplásmico & 9410 & 3 \\
\hline & Astrocitoma gemistocítico & 9411 & 3 \\
\hline Grau III & Astrocitoma anaplásico & 9401 & 3 \\
\hline \multirow[t]{3}{*}{ Grau IV } & Glioblastoma (Multiforme) & 9440 & 3 \\
\hline & Glioblastoma de células gigantes & 9441 & 3 \\
\hline & Gliossarcoma & 9442 & 3 \\
\hline \multicolumn{4}{|c|}{ Outras variantes } \\
\hline \multicolumn{2}{|c|}{ Xantoastrocitoma pleomórfico (Grau II ou III) } & 9424 & 3 \\
\hline \multicolumn{2}{|c|}{ Astrocitoma subependimário de células gigantes (Grau I) } & 9384 & 1 \\
\hline \multicolumn{4}{|c|}{ Gliomas mistos } \\
\hline \multicolumn{2}{|c|}{ Oligoastrocitoma (Grau II) } & 9382 & 3 \\
\hline \multicolumn{2}{|c|}{ Oligoastrocitoma anaplásico (Grau III) } & 9382 & 3 \\
\hline \multicolumn{4}{|c|}{ Tumores neuronais e neurogliais } \\
\hline \multicolumn{2}{|c|}{ Astrocitoma infantil desmoplásico (Grau I) } & 9412 & 1 \\
\hline
\end{tabular}

${ }^{1}$ Código adotado pela Classificação Internacional de Doenças para Oncologia (ICD-O) e pela Nomenclatura Sistematizada em Medicina (SNOMED). ${ }^{2}$ O comportamento biológico tumoral é qualificado em (0) benigno, (1) malignidade baixa, limitrofe ou incerta, (2) lesões in situ e (3) maligno. Adaptado de Kleihues et al..$^{22}$.

redor de vasos sangüíneos origina o aspecto de "pseudorosetas" perivasculares. A degeneração dos processos fibrilares resulta na deposição de corpos eosinofílicos brilhantes, classicamente descritos como em "forma de salsicha" - as fibras de Rosenthal, típicas desses tumores. Pode haver considerável pleomorfismo nuclear, todavia este não está associado com fenômenos anaplásicos ou aumento de celularidade. Mitoses são raras, comumente ausentes. A proliferação vascular pode ser extensa, contudo sua presença não representa malignidade nesses tumores (Figura 2[b]) ${ }^{29}$.

\section{Astrocitomas grau II (OMS)}

São neoplasias com alto grau de diferenciação celular, baixo crescimento e potencial infiltrativo sobre estruturas contíguas. Podem ser localizados em qualquer parte do SNC. Mostram-se como massas homogêneas, de bordos mal definidos, ocasionalmente com a formação de cistos. A histopatologia demonstra aumento irregular da densidade celular com atipia nuclear e pleomorfismo proeminentes. Nas áreas mais compactas, os processos citoplasmáticos formam uma rede fibrilar, de aspecto microcístico. Usualmente não são visualizadas figuras mitóticas. De acordo com o tipo celular predominante, três variantes podem ser distinguidas: (1) Fibrilar, a mais freqüente, com citoplasma escasso e núcleos hipercromáticos anômalos; (2) Gemistocítico, na qual predominam células de citoplasma abundante e eosinofílico, com núcleos excêntricos, repousando sobre denso fundo fibrilar (denominadas por gemistócitos); e (3) Protoplásmico, a mais rara, formada por pequenos astrócitos neoplásicos com discretos processos filamentosos (Figura $2[\mathrm{c}, \mathrm{d}, \mathrm{e}])^{19}$.

\section{Astrocitomas grau III (OMS) - astrocitoma anaplásico}

Apresentam-se como tumores de contornos irregulares com tendência infiltrativa. Surgem em qualquer local do $\mathrm{SNC}$ e demonstram rápido crescimento. Microscopicamente, observa-se aumento da celularidade (multifocal ou difusa) associada a marcante pleomorfismo e atipia nuclear. Detectam-se ainda células astrocíticas pouco diferenciadas e freqüentes figuras mitóticas. Podem ocorrer pequenos focos de necrose e de proliferação endotelial, indicando potencial progressão ao grau IV (Figura 2 [f]) 44. $^{4}$.

\section{Astrocitomas grau IV (OMS) - glioblastoma multiforme}

Representam os neoplasmas mais malignos de origem astrocítica. Podem desenvolver-se a partir de astrocitomas grau II ou III, quando são designados de "secundários", ou surgirem de novo, sem evidências de lesões precursoras, sendo denominados de "primários". Localizam-se preferencialmente nos hemisférios cerebrais, particularmente nas regiões fronto-temporal 

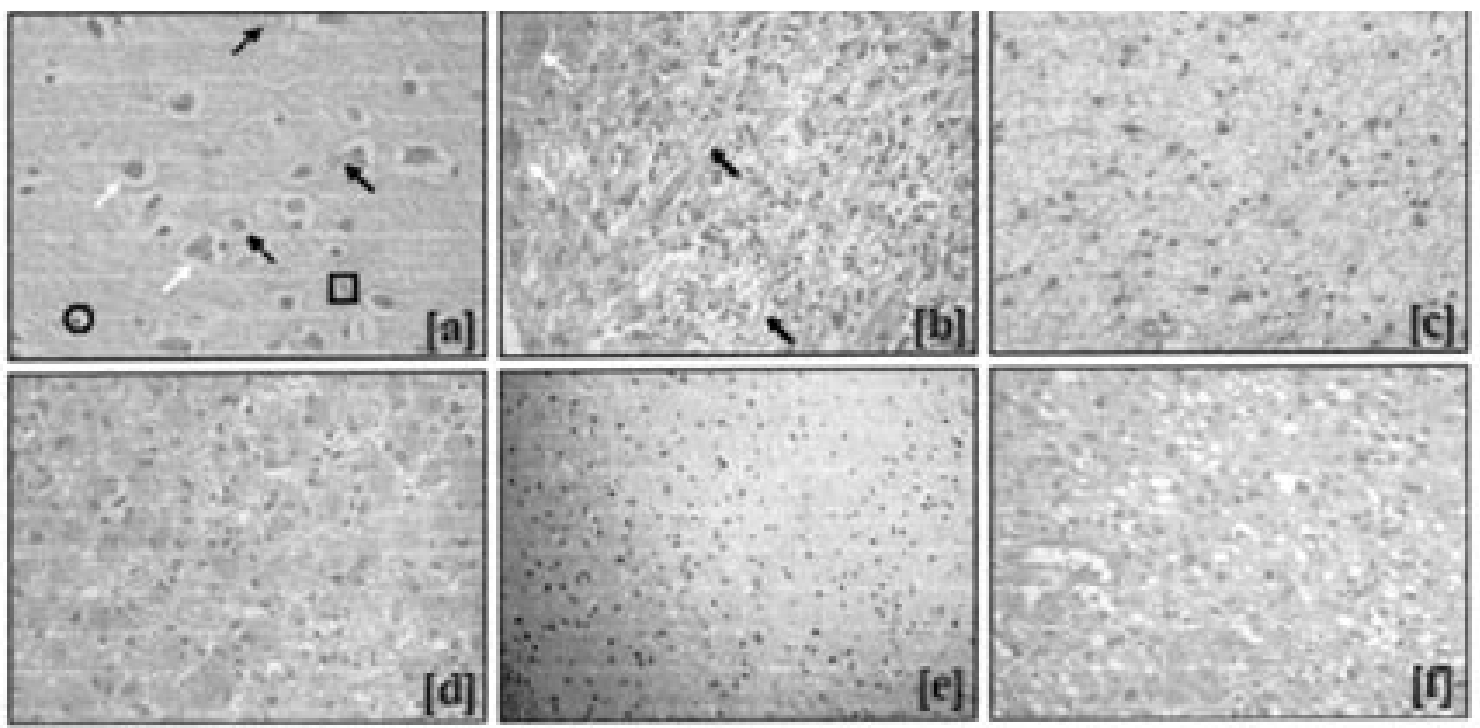

Figura 2 - Histopatologia dos tumores astrocíticos $(\boldsymbol{H E}, 400 X)$. [a] Córtex cerebral não-tumoral: observam-se corpos celulares de neurônios piramidais, de formato triangular (setas brancas); astrócitos normais, com núcleos grandes, arredondados e mais "frouxos" (setas pretas); células da micróglia, de núcleos densos, alongados e em forma de vírgula (quadrado) e oligodendrócitos, com núcleos redondos (menores que os dos astrócitos), densos e circundados por um halo claro (círculo). [b] Astrocitoma pilocítico cerebelar, grau I (OMS): percebe-se proliferação de astrócitos discretamente atípicos sob densa matriz fibrilar, com áreas de degeneração microcística, onde figuram fibras de Rosenthal (setas pretas). O tecido tumoral desenvolve-se entre o tecido cerebelar não-tumoral, sendo visualizadas células de Purkinje (setas brancas). [c] Astrocitoma fibrilar, grau II (OMS): evidencia-se baixa celularidade, com núcleos ovais e hipercromáticos sob fundo fibrilar. [d] Astrocitoma gemistocítico, grau II (OMS): predominam células de citoplasma abundante e eosinofílico, com núcleos excêntricos, repousando sobre compacta matriz fibrilar. [e] Astrocitoma protoplásmico, grau II (OMS): percebe-se pequenos astrócitos neoplásicos com escasso citoplasma. [f] Astrocitoma anaplásico, grau III (OMS): nota-se moderada celularidade, composta por astrócitos atípicos, pleomórficos, com núcleos irregulares e hipercromáticos. Há ainda discreta proliferação endotelial, raras mitoses e degeneração microcística.

e parietal. A despeito do rápido crescimento e do grande potencial infiltrativo, raramente invadem o espaço subaracnóideo e, assim, dificilmente produzem metástases. Histologicamente, demonstram grande heterogeneidade. $\mathrm{O}$ exuberante pleomorfismo celular manifesta-se através de células bipolares, fusiformes, fasciculadas, pequenas (indiferenciadas) ou gigantes, contendo inclusões lipídicas e granulações citoplasmáticas. Os núcleos são comumente aberrantes, por vezes múltiplos. A presença de necrose (secundária ao insuficiente suprimento sangüíneo tumoral) ocorre de duas formas distintas: em grandes áreas necróticas, com focos hemorrágicos dispersos, ou em pequenas clareiras irregulares, múltiplas, rodeadas por pequenas células tumorais fusiformes. Esta última, designada como necrose geográfica ou em pseudopaliçada, configura achado típico dos glioblastomas. A proliferação microvascular é outra marca histológica dos tumores do grau IV, aparecendo como tufos de aspecto glomerulóide, rodeando as áreas necróticas. Admite-se que a hiperplasia endotelial resulta de estímulos neoangiogênicos sobre capilares preexistentes e/ou do remodelamento vascular, através da mobilização de pericitos e células musculares lisas. Podem ainda ocorrer focos de metaplasia epitelial, exibindo "rolhas" queratínicas, bem como aglomerados de linfócitos perivasculares. As duas variantes histológicas desses tumores são: (1) o glioblastoma de células gigantes, com o predomínio de células gigantes multinucleadas bizarras assentadas sobre estroma rico em reticulina; e (2) o gliossarcoma, com áreas tumorais variando entre o aspecto gliomatoso e o mesenquimal, manifestando diferenciação condróide, osteóide, rabdóide entre outras (Figura 3$)^{11}$.

\section{Outros tipos histológicos}

O xantoastrocitoma pleomórfico é uma variante rara, caracterizado pela presença de células pleomórficas com inclusões lipídicas, geralmente envolvidas por fibras reticulínicas. $\mathrm{O}$ astrocitoma subependimário de células gigantes constitui entidade benigna, derivada das lesões hamartomatosas associadas à esclerose tuberosa, sendo caracterizada pela mistura de populações celulares heterogêneas sobre uma matriz fibrilar. Os tumores mistos (oligo-astrocíticos) representam a "colisão" entre fenótipos tumorais astrocíticos e oligodendrocíticos. Já o astrocitoma infantil desmoplásico é formado por agregado de células pouco diferenciadas, com predomínio de astrócitos neoplásicos, distribuído sobre abundante matriz conjuntiva ${ }^{40}$. 

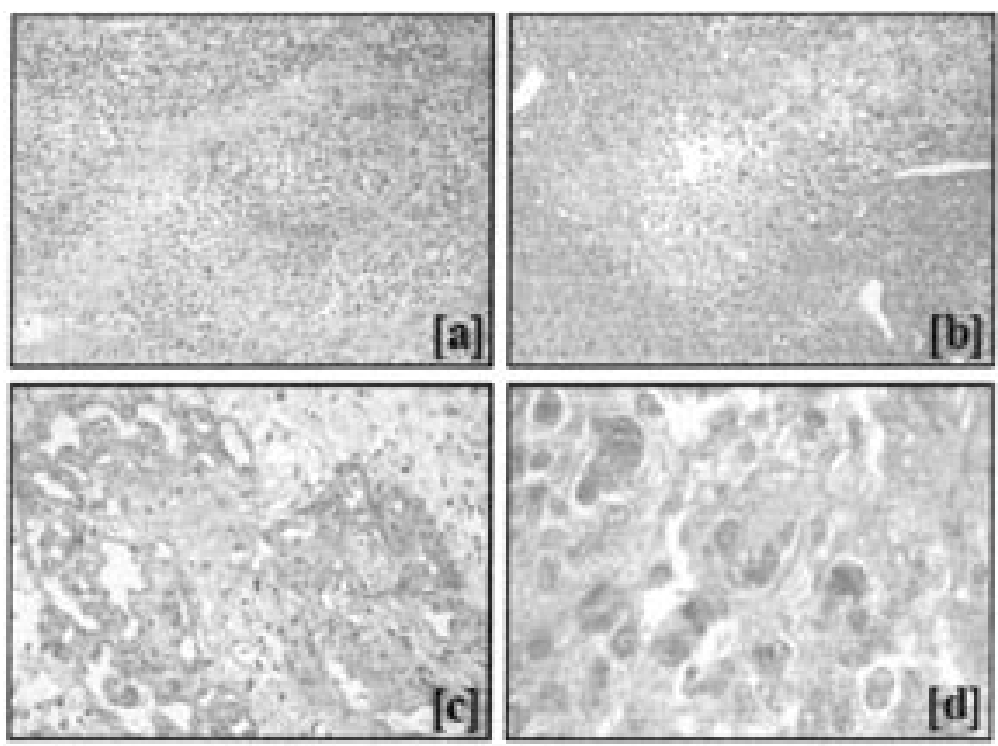

Figura 3 - Características histopatológicas dos astrocitomas grau IV (Glioblastoma multiforme).

[a] Visão geral. Há significativo aumento da celularidade, expressivo pleomorfismo celular, áreas de proliferação endotelial e abundante necrose (HE, 200X); [b] Área de necrose em pseudopaliçada (HE, 200X); [c] Proliferação endotelial de aspecto glomerulóide (HE, 400X); [d] Células gigantes multinucleadas (HE, 1000X).

Apesar das distinções entre os diferentes graus dos astrocitomas serem também sugeridas por particularidades epidemiológicas (Tabela 2) e radiológicas (Figura 4), a rotina diagnóstica histopatológica permanece extremamente laboriosa, sendo marcada pela subjetividade e pela imprecisão.

\section{Genética molecular}

Os recentes avanços na área da biologia molecular apontam as distinções entre os diferentes graus dos astrocitomas como reflexo de alterações genéticas específicas. Tais eventos moleculares seriam responsáveis não só pela promoção, mas também pela progressão tumoral em malignidade, conduzindo fenótipos de baixa gradação a categorias mais elevadas.
Os astrocitomas grau I exibem irregularidades genéticas distintas dos demais graus, o que reforça a teoria de rara progressão para fenótipos mais malignos. Estudos citogenéticos demonstram variação cariotípica de normal a aberrante, com ganho dos cromossomos 7, 8 e 22 e ganho ou deleção do cromossomo 19. Ocasionalmente, detectam-se perdas no cromossomo $17 \mathrm{q}$, incluindo a região codificadora do gene NF1. A neurofibromina, produto do gene NF1, possui funções supressoras tumorais, fazendo crer que a desregulação desse gene poderia assumir papel relevante na evolução para o astrocitoma pilocítico ${ }^{30}$.

A formação do astrocitoma grau II é associada a, pelo menos, três alterações: inativação do gene supressor tumoral p53, perda do cromossomo $22 \mathrm{q}$ e ativação do fator de crescimento derivado de plaqueta (PDGF, de PlateletDerived Growth Factor) e/ou do seu receptor ${ }^{22}$.

A alteração do p53 foi um dos primeiros eventos identificados na tumorigênese dos astrocitomas, sendo

Tabela 2

Dados epidemiológicos referentes aos tumores astrocíticos diagnosticados nos EUA, no período de 1997 a 2001 , distribuídos de acordo com a graduação histológica da OMS.

\begin{tabular}{|c|c|c|c|c|c|c|}
\hline $\begin{array}{c}\text { Grau } \\
\text { Histológico } \\
\text { (OMS) }\end{array}$ & $\begin{array}{l}\text { Percentual entre } \\
\text { os tumores } \\
\text { primários do SNC }\end{array}$ & $\begin{array}{c}\text { Percentual } \\
\text { entre os } \\
\text { astrocitomas }\end{array}$ & $\begin{array}{c}\text { Média de } \\
\text { idade ao } \\
\text { diagnóstico }\end{array}$ & $\begin{array}{c}\text { Proporção } \\
\text { masculino/ } \\
\text { feminino }\end{array}$ & $\begin{array}{c}\text { Percentual médio } \\
\text { de sobrevida } \\
\text { em } 5 \text { anos }\end{array}$ & $\begin{array}{c}\text { Incidência anual } \\
\text { (por } 100.000 \\
\text { habitantes) }\end{array}$ \\
\hline I & 2,30 & 7,46 & 12 & 1,09 & 90,80 & 0,483 \\
\hline II & 9,30 & 14,70 & 43 & 1,24 & 41,90 & 0,952 \\
\hline III & 3,40 & 10,84 & 51 & 1,32 & 29,70 & 0,701 \\
\hline IV & 21,00 & 67,00 & 64 & 1,28 & 3,40 & 4,345 \\
\hline Total & 36,00 & 100,00 & 55 & 1,26 & 18,43 & 6,470 \\
\hline
\end{tabular}

Fonte: CBTRUS (Central Brain Tumor Registry of the United States) 5. 

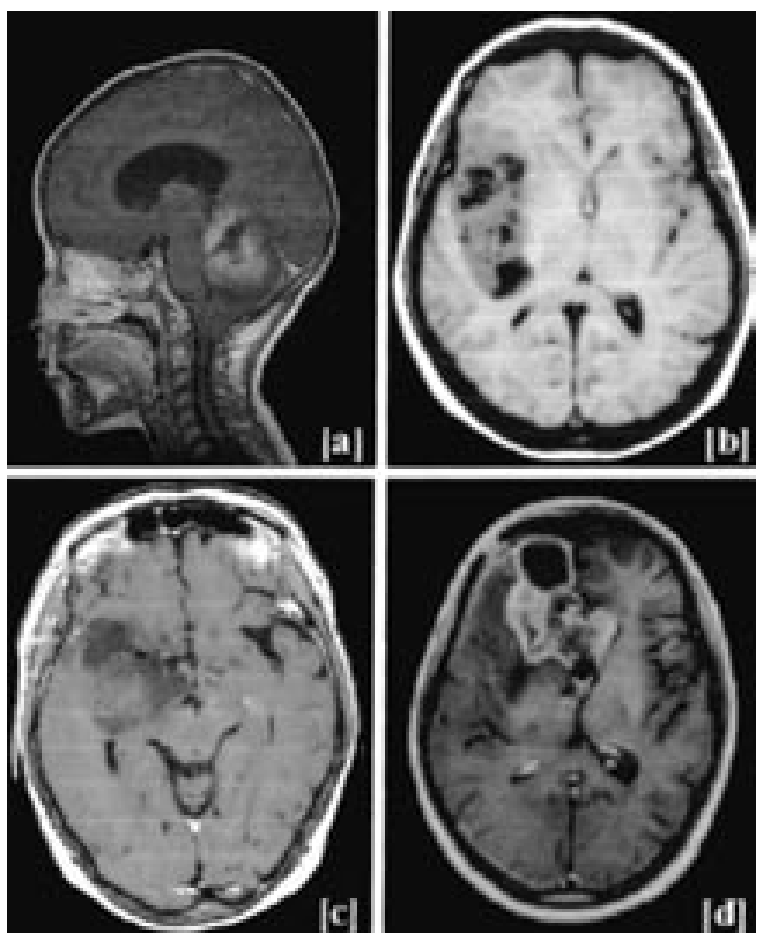

Figura 4 - Estudos por ressonância magnética nuclear em T1 representativos dos tumores astrocíticos. [a] Astrocitoma pilocítico, grau I (OMS): corte sagital com contraste paramagnético (gadolínio) demonstrando massa cística cerebelar isointensa com nodulações discretamente captantes; há deslocamento anterior do tronco cerebral e hidrocefalia obstrutiva. [b] Astrocitoma fibrilar, grau II (OMS): corte axial revela lesão frontoinsular hipointensa à direita, mal definida, com componentes císticos; percebe-se deslocamento e compressão do lobo frontal direito. [c] Astrocitoma anaplásico, grau III (OMS): corte axial mostra massa fronto-parietal hipodensa, mal delimitada; observa-se edema peritumoral com deslocamento da linha média. [d] Glioblastoma multiforme, grau IV (OMS): corte axial após contraste paramagnético (gadolínio) exibindo lesão frontal bilateral (predomínio à direita), irregular, com captação de contraste (aspecto anelar multifocal); as áreas centrais hipointensas correspondem à necrose.

considerada uma etapa inicial. O gene p53 (cromossomo $17 \mathrm{p}$ ) codifica o fator de transcrição homônimo que participa de inúmeros programas celulares, incluindo a regulação do ciclo celular, a resposta aos danos ao DNA e a apoptose. Sua inativação, usualmente por mutação de uma cópia e perda cromossômica do alelo restante, é descrita em aproximadamente $60 \%$ de todos os tumores astrocíticos ${ }^{7}$.

A perda do cromossomo 22 q é detectada em $20 \%$ a $30 \%$ dos astrocitomas, sugerindo a possível localização de um gene supressor tumoral neste cromossomo. Análises com hibridação genômica comparativa (CGH, de Comparative Genomic Hybridisation) destacam outras alterações cromossômicas (ganho do 7q, amplificação do 8 e deleção do 6) como potencialmente envolvidas no surgimento dos astrocitomas ${ }^{29}$.

Dos vários fatores de crescimento expressos pelos astrocitomas, o PDGF é o mais claramente implicado no processo tumorigênico, especialmente nos tumores do grau II. O mecanismo de superexpressão do PDGF, bem como de seu receptor (PDGFR), ainda não foi totalmente esclarecido, embora alguns tumores demonstrem amplificação do gene codificador do PDGFR subtipo alfa. A expressão de PDGF também se correlaciona com a inativação do $\mathrm{p} 53^{28}$.

A transição para o astrocitoma grau III é vinculada à inativação de genes supressores tumorais nos cromossomos 9p e 13q, bem como à amplificação do cromossomo 12q. A perda do cromossomo 13q é observada em um terço dos astrocitomas, sendo o sítio 13q13 o local do gene codificador da $\mathrm{pRb}$. A perda ou mutação dos genes supressores tumorais p16 (CDKN2A) e p15 (CDKN2B) (localizados no cromossomo 9p21), bem como o aumento da expressão ou amplificação do gene da CDK4 (situado no cromossomo 12q), também parecem convergir no sentido da não-expressão ou da ativação por fosforilação da proteína $R b(p R b)$, provocando a liberação dos fatores de transcrição E2F (promotores da transição G1-S) ${ }^{24,31}$.

Outro gene associado à progressão para o grau III consiste em suposto supressor tumoral localizado no cromossomo 19q. A perda do cromossomo 19q parece ocorrer exclusivamente em tumores gliais, sendo detectada em todos os graus dos astrocitomas, especialmente no astrocitoma grau III $(44 \%)^{7}$.

Distintas vias moleculares podem caracterizar a progressão para o glioblastoma: uma comumente observada em pacientes jovens, a partir dos astrocitomas grau II ou III (astrocitoma grau IV secundário); e outra típica em pacientes idosos, sem história de astrocitoma de baixo grau precedente, originada diretamente das células precursoras (astrocitoma grau IV primário). Todavia, a perda do cromossomo 10 é relatada como evento comum a todos os astrocitomas grau IV, sendo encontrada em $60 \%$ a $85 \%$ desses tumores ${ }^{18,21}$.

$\mathrm{O}$ astrocitoma grau IV secundário demonstra perda de heterozigose em grandes regiões do cromossomo 10 (10p, 10q23 e 25-26). O gene supressor tumoral PTEN/MMAC1 (de Phosphatase and TENsin homology / Mutated in Multiple Advanced Cancer 1), situado no cromossomo 10q23, também pode aparecer mutado nos tumores grau IV. O gene DCC (de Deleted in Colon Cancer), outro supressor tumoral localizado no cromossomo $18 \mathrm{q} 21$, está ausente em $7 \%$ dos astrocitomas de baixo grau e em $53 \%$ dos glioblastomas, sugerindo sua participação na gênese desses tumores. O gene DMBT1 (de Deleted in Malignant Brain Tumours 1), situado no cromossomo 10q25-26, encontra-se deletado em 23\% a $38 \%$ dos astrocitomas grau IV secundários, sendo considerado mais um candidato a supressor tumoral ${ }^{22}$.

No astrocitoma grau IV primário ocorre a amplificação do receptor do fator de crescimento epidérmico 
(EGFR, de Epidermal Growth Factor Receptor) na maioria dos casos, simultaneamente à perda do cromossomo 10. O EGFR consiste em um receptor de membrana do tipo tirosino-quinase envolvido no controle da proliferação celular ${ }^{30}$.

Julga-se que menos de $10 \%$ dos glioblastomas primários exibam mutação do p53, não sendo verificada concomitância entre esta e a superexpressão de EGFR. Tal fato indica que esses eventos são mutuamente exclusivos, reiterando a diferença entre a progressão para os tumores de novo e para os secundários, sendo nestes últimos tipicamente detectada a mutação do p53. Entretanto, a atividade transcricional da proteína p 53 nos astrocitomas grau IV primários está algumas vezes abolida, visto a formação de complexos com a proteína MDM2 (de Murine Double Minute clone 2). O gene MDM2, encontrado no cromossomo 12q13-14, é descrito como superexpresso em $50 \%$ dos glioblastomas primários ${ }^{7}$.
Ainda quanto à progressão para os tumores grau IV, a desregulação do gene CDKN2A ocasiona a perda da expressão do supressor tumoral p16 o que, por sua vez, promove a superexpressão/amplificação de CDKs (de Cyclin-Dependent Kinase) e a fosforilação da $\mathrm{pRb}$. A promoção destas vias é observada em 36\% dos astrocitomas grau IV primários, contrastando com $4 \%$ nos tumores secundários. Outro subconjunto dos glioblastomas é formado por aqueles provenientes da evolução de oligodendrogliomas e oligoastrocitomas, caracterizados pela perda dos cromossomos $19 \mathrm{q}$ e $1 \mathrm{p}$, além do $10^{27}$.

Resumidamente, os astrocitomas malignos podem originar-se através de diferentes caminhos moleculares: a partir de astrocitomas de baixo grau, via inativação do p53; de novo, no decurso da ativação do EGFR; de neoplasmas oligodendrogliais; ou ainda por direções até então não definidas (figura 5).

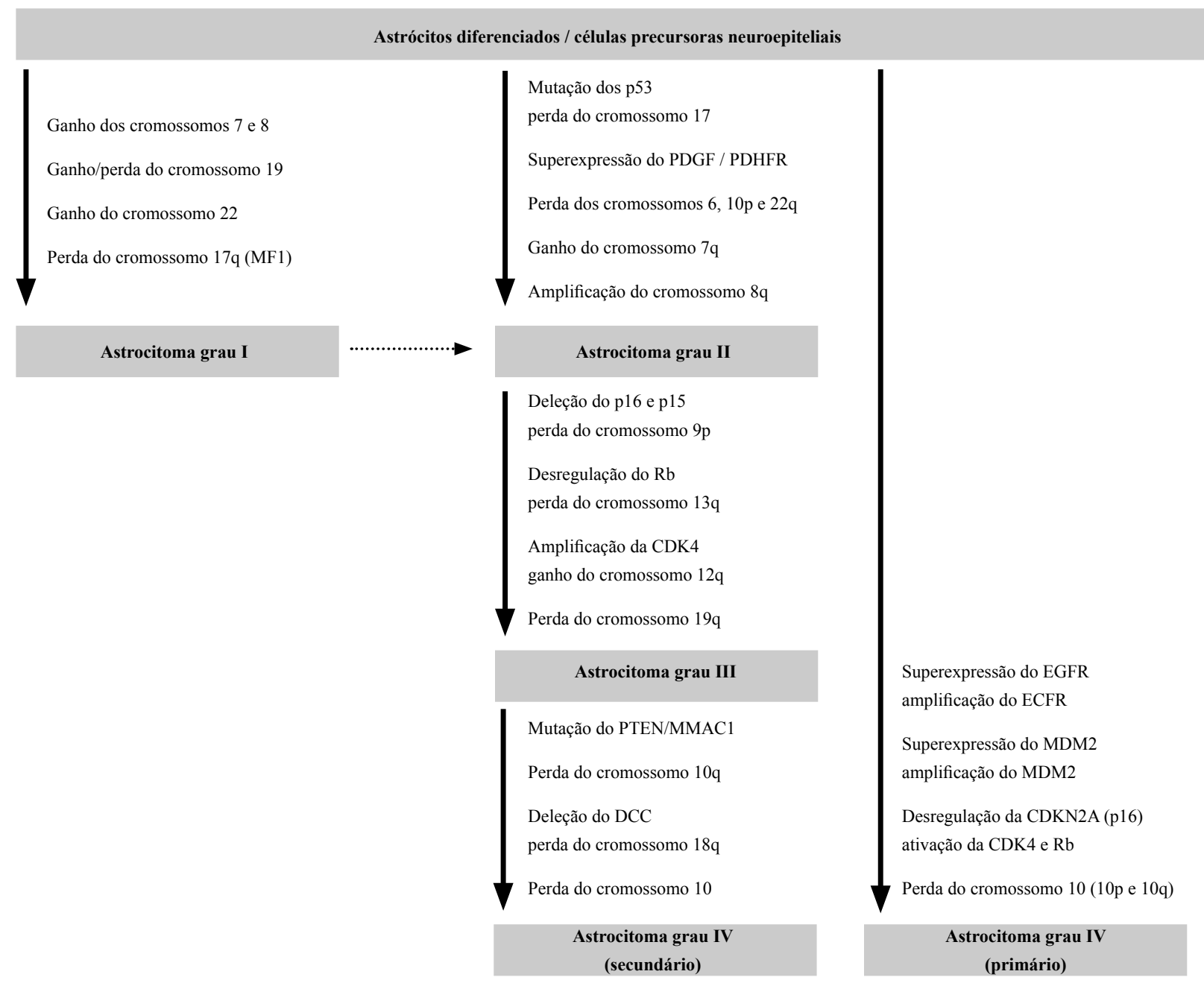

Figura 5 - Diagrama representativo das alterações genéticas envolvidas na progressão maligna dos astrocitomas. Adaptado de Kleihues e Cavenee ${ }^{22}$. 


\section{Aspectos clínicos}

Enquanto a duração da história clínica e as perspectivas de sobrevida estão mais diretamente relacionadas ao comportamento biológico do tipo tumoral, os sintomas determinados pelos astrocitomas dependem primariamente da localização dessas neoplasias no $\mathrm{SNC}^{15}$.

Os astrocitomas cerebelares geralmente cursam com ataxia, náuseas e disfunções dos pares cranianos. Nos gliomas do nervo óptico podem ser observadas redução da acuidade visual e irregularidades no campo visual. Neoplasias do tronco cerebral promovem déficits relacionados aos nervos cranianos. $\mathrm{O}$ acometimento neoplásico hipotalâmico é tipicamente associado a síndromes endócrinas (puberdade precoce, diabetes insípido entre outras), desequilíbrio hidroeletrolítico e desregulação autonômica ${ }^{25}$.

Entre os tumores supratentoriais, aqueles que se manifestam nos lobos frontais e/ou parietais costumam ocasionar epilepsia, hemiparesia e transtornos de personalidade. Já os temporais, além de crises convulsivas, favorecem o aparecimento de distúrbios da fala e da linguagem. Qualquer uma dessas lesões que promova oclusão ou obstrução das vias de drenagem do fluido cérebro-espinhal pode desencadear aumento da pressão intracraniana, levando ao aparecimento de cefaléia, papiledema e vômitos ${ }^{1}$.

\section{Terapêutica}

A remoção cirúrgica, total ou parcial, continua sendo a principal abordagem terapêutica contra os tumores do SNC. A máxima extirpação do tecido tumoral, o mais precocemente possível, pode resultar em cura. Outros benefícios da terapia cirúrgica consistem na possibilidade de definição precisa do diagnóstico histopatológico, na reversão dos déficits neurológicos instalados e na minimização dos riscos de progressão tumoral. Contudo, o potencial infiltrativo da maioria dos astrocitomas, bem como a capacidade de migração local das células tumorais, pode tornar a intervenção cirúrgica inexeqüível ou ineficaz. Além disso, a cirurgia pode agravar ou mesmo desencadear morbidades neurológicas ${ }^{11,29}$.

A radioterapia é usualmente empregada no tratamento dos astrocitomas de alto grau (III e IV), ao passo que seus benefícios no tratamento de tumores de baixo grau (I e II) despertam controvérsias. Considerando os efeitos deletérios da radiação sobre tecidos sadios, a prática atual restringe o uso da radiação focal somente para tumores de limites precisos, utilizando em média 60 Grays como dose total ${ }^{46}$.
A quimioterapia tem demonstrado importante papel adjuvante no tratamento de tumores astrocíticos de baixo grau em crianças ${ }^{4}$. Todavia, agentes quimioterápicos isoladamente ou associados à radioterapia não têm revelado aumentos significativos na sobrevida dos pacientes. As principais drogas utilizadas em esquemas contra os astrocitomas constam de nitrosuréias [nimustina (ACNU); carmustina (BCNU); lomustina (CCNU)], demais alquilantes (procarbazina; temozolomida), alcalóides (vincristina), compostos platínicos (carboplatina; cisplatina) e inibidores da topoisomerase I (topotecano; irinotecano). A pouca eficácia da quimioterapia no tratamento dos tumores do SNC tem sido apontada como resultado da baixa penetração dos fármacos nos tecidos (causada pela seletividade da barreira hematencefálica e pela coesão dos conjuntos celulares adjacentes aos tumores), bem como pela resistência primária ou adquirida aos diferentes quimioterápicos ${ }^{39}$.

Há ainda uma significativa proporção de pacientes portadores de astrocitomas de baixo grau que são seguidos conservadoramente, sendo tratados unicamente com anticonvulsivantes e acompanhados por neuroimagem.

Quanto aos tumores de alto grau reicidivantes, $20 \%$ dos pacientes são candidatos à nova cirurgia. Novas radiações são limitadas pela toxicidade, mas os pacientes podem ser conduzidos à radiocirurgia por esterotaxia (gamma knife, implantes radioativos) ${ }^{20} \mathrm{ou}$ braquiterapia intersticial ${ }^{34}$.

No Brasil, a abordagem cirúrgica prevalece ainda mais sobre a radioterapia e a quimioterapia no tratamento dos tumores astrocíticos. O difícil acesso aos serviços especializados, assim como aos métodos de neuroimagem, resultam em freqüente retardamento diagnóstico. Por sua vez, este atraso corrobora para redução das possibilidades quanto ao uso da radiação ou mesmo da ressecabilidade tumoral. Raros casos são designados à quimioterapia devido ao insucesso e, por vezes, à indisponibilidade das drogas específicas dos esquemas contra tumores do SNC. Recursos mais avançados, como radiocirurgia e neuronavegação, ainda são pouco disponíveis.

\section{Perspectivas terapêuticas}

A identificação das principais alterações moleculares envolvidas no processo neoplásico desvenda a possibilidade da elaboração de estratégias terapêuticas dirigidas especialmente para o bloqueio desses fenômenos. As terapias alvo-direcionadas prometem significativos avanços no tratamento dos astrocitomas através do desenvolvimento de agentes mais específicos, menos tóxicos, menos indutores de resistência e, portanto, mais efetivos. 
Uma das novas abordagens consiste na inibição da expressão e/ou da atividade das CDKs nas células tumorais, impedindo a progressão do ciclo celular e, assim, ativando mecanismos apoptóticos. O flavopididol, um inibidor sintético não-específico de CDKs, aparece como promissor exemplo dessa classe, já figurando em estudos clínicos ${ }^{37}$. Outra alternativa seria a restauração ou a reintrodução dos inibidores naturais das CDKs (genes supressores tumorais) quando estes estivessem mutados. A terapia genética com o gene p53, introduzido através de vetores virais ou lisossomos catiônicos, têm demonstrado sucesso no bloqueio da ciclagem celular e reativação da apoptose, melhorando a resposta de algumas neoplasias (incluindo os astrocitomas) à quimioterapia convencional ${ }^{6}$.

Outro potencial alvo molecular é representado pelo conjunto de receptores de superfície celular do tipo tirosino-quinase. Múltiplos agentes, compreendendo anticorpos monoclonais, moléculas inibitórias e imunotoxinas, têm sido desenvolvidos na tentativa de coibir os subtipos específicos desses receptores envolvidos na transformação e progressão neoplásicas ${ }^{33}$. O imatinibe foi a primeira droga produzida a partir desse conceito, atuando no bloqueio do domínio tirosino-quinase das proteínas $a b l-b c r$ na leucemia mielóide crônica ${ }^{41}$.

O impacto positivo do trastuzumabe (um anticorpo monoclonal recombinante bloqueador do receptor ErbB2) no tratamento do câncer de mama avançado abriu caminho para a geração dos agentes específicos contra os receptores da família $\mathrm{ErbB}^{8}$. O gefitinibe, um inibidor seletivo do EGFR já em uso no carcinoma de pulmão metastático, vem apresentando bons resultados experimentais na sensibilização de gliomas malignos à radio e à quimioterapia ${ }^{38}$. Novas preparações como o erlotinibe (inibidor do domínio intracitoplasmático do EGFR), o cetuximabe (anticorpo monoclonal contra a porção extracelular do EGFR) e o canertinibe (inibidor irreversível pan-ErbB) encontram-se em adiantadas fases de diversos ensaios clínicos ${ }^{16}$.

Ainda com relação às vias de sinalização nas células tumorais, surge também a possibilidade do bloqueio das moléculas transdutoras intracelulares. A inibição da enzima farnesil-transferase tem-se mostrado promissor artifício de inativação das proteínas Ras. A farnesilação (adição pós-traducional de resíduos de 15 a 20 carbonos no domínio C-terminal) promove a ativação e ancoragem à membrana citoplasmática desse grupo de proteínas, tornando-as responsivas aos estímulos por parte dos receptores de membrana ${ }^{9}$. Nesse sentido, drogas que suprimem a atividade catalítica das enzimas farnesiltransferases, como o lonafarnibe e o tipifarnibe, têm mostrado eficácia no tratamento de tumores sólidos com mutação da proteína $\operatorname{Ras}^{36}$. Ensaios com portadores de tumores astrocíticos não detectaram respostas objetivas à terapia com esses agentes, embora alguns pacientes tenham demonstrado estabilização da doença ${ }^{10}$.

A inibição dos fatores implicados na angiogênese tumoral representa mais uma nova tendência no tratamento dos tumores astrocíticos, especialmente os de alto grau. O reconhecimento de distúrbios moleculares e de mecanismos fisiológicos ativadores dos fenômenos angiogênicos delimitou alvos terapêuticos específicos, possibilitando a elaboração de diversas abordagens. Dentre as terapias anti-angiogênicas atualmente em avaliação clínica, destacam-se os inibidores de proteases (velcade), os antagonistas dos fatores/receptores VEGF (de Vascular Endothelial Growth Factor) (bevacizumabe, semaxanibe), os inibidores das integrinas (talidomida, cilengitide), as toxinas endoteliais (atrasentana), os inibidores das metaloproteinases (marimastate, prinomastate), os supressores naturais da angiogênese (angiostatina) e os inibidores da ciclooxigenase-2 (celecoxibe) ${ }^{43}$.

Outra vertente terapêutica aponta para o direcionamento do sistema imunológico no sentido do reconhecimento e eliminação especificamente das células astrocíticas tumorais. Esta tarefa apresenta-se como um grande desafio, visto os versáteis mecanismos de escape imunológico desenvolvido pelas células neoplásicas. Todavia, a expressão diferencial de antígenos nas células cancerosas como resultado de mutações ou alterações regulatórias nos p roto-oncogenes têm possibilitado consideráveis progressos ${ }^{32}$. As propostas imunoterápicas abrangem a imunização passiva com anticorpos monoclonais (rituximabe), a imunização passiva com células $\mathrm{T}$ ou natural killer ativadas, o uso de citocinas imunomoduladoras (L-2), a transfecção com os genes das citocinas (IL-12), a reversão da imunossupressão tumoral (bloqueio do TGF- $\beta 2$ ), bem como o uso de vacinas anticâncer desenvolvidas a partir de peptídeos tumorais ou com células dendríticas ativadas ${ }^{26}$.

Uma das mais recentes promessas na terapia molecular dos astrocitomas é representada pelas ferramentas de silenciamento genético pós-transcricional. Nestas, a inibição se dá através não mais da proteína oncogênica, mas sim do seu transcrito (RNA mensageiro, RNAm). O princípio da técnica consiste na introdução de moléculas de RNA complementar (RNA antisense) ou pequenos fragmentos de RNA (RNA interference) nas células neoplásicas. Estes, por sua vez, reconhecem seqüências específicas de transcritos oncogênicos, formando RNAs dupla-fita híbridos que são em seguida degradados por ribozimas ${ }^{17}$. A constatação do livre acesso dos RNAs antissenso e de interferência através da barreira hematencefálica desperta ainda mais o interesse nessa estratégia como potencial abordagem contra tumores do $\mathrm{SNC}^{12}$.

Nesse contexto, a conjunção entre o conhecimento dos distúrbios moleculares ativadores do processo 
tumorigênico, o uso racional da quimioterapia clássica e a aplicação das novas estratégias alvo-direcionadas sugere um novo tempo na prática neuro-oncológica, onde a abordagem individualizada e molecularmente guiada definirá a terapêutica antineoplásica.

\section{Referências}

1. ROOPER AH, Brown RH: Adams \& Victor's principles of neurology. Ed 8. Washington, McGraw-Hill, 2005, 1500p.

2. BAILEY P, CUSHING $\mathrm{H}$ : A classification of tumors of the gliomas group on a histogenetic basis with a correlated study of prognosis. Philadelphia, Lippincott, 1926, 95p.

3. BURGER PC, SCHEITHAUER B, VOGEL FS: Surgical pathology of nervous system and its coverings. Ed 4. Glasgow, Arnold Publishers, 2002, 672p.

4. CASTELO MA, SCHIAVETTI A, VARRASSO G, CLERICO A, CAPPELLI C: Chemotherapy in low-grade astrocytoma management. Childs Nerv Syst 14:6-9, 1998.

5. CBTRUS: Statistical report: primary brain tumors in the United States (1997-2001). Chicago, Central Brain Tumor Registry of the United States, 2004.

6. CHANG EH, PIROLLO KF, BOUKER KB: Tp53 gene therapy: a key to modulating resistance to anticancer therapies? Mol Med Today 6:358-64, 2000.

7. CHOSDOL K, CHATTOPADHYAY P, SINHAS: Molecular pathways of glial tumorigenesis. Curr Sci 82(6):648-54, 2002.

8. COBLEIGH MA, VOGEL CL, TRIPATHY D et al:: Multinational study of the efficacy and safety of humanized anti-HER2 monoclonal antibody in women who have HER2-overexpressing metastático breast cancer that has progressed after chemotherapy for metastatic disease. J Clin Oncol 17(9):2639-48, 1999.

9. CRUL M, DE KLERK GJ, BEIJNEN JH, SCHELLENS JH: Ras biochemistry and farnesyl transferase inhibitors: a literature survey. Anticancer Drugs 12(3):163-84, 2001.

10. DELMAS C, HELIEZ C, COHEN-JONATHAN E, END D, BONNET J, FAVRE G, TOULAS C: Farnesyltransferase inhibitor, R115777, reverses the resistance of human glioma cell lines to ionizing radiation. Int $\mathrm{J}$ Cancer 100(1):43-8, 2002.

11. ELLISON D, LOVE S, CHIMELLI L, HARDING BN, LOWE J, VINTERS HV: Neuropathology: a reference text of CNS pathology. Ed 2. Philadelphia, Mosby, 2004, 754p.

12. FAN QW, WEISS WA: RNA interference against a glioma-derived allele of EGFR induces blockade at G(2)M. Oncogene 24(5):829-37, 2005.

13. FIELDS RD, STEVENS-GRAHAN B: New insights into neuron-glia communication. Science 298:556-62, 2002.

14. GRAY F, DE GIROLAMI U, POIRIER J: Escourolle and Poirier manual of basic neuropathology. Ed 4. Philadelphia, Butterworth Heinemann Health, 2004, 416p.

15. GREEMBERG DA, AMINOFF MJ, SIMON RP: Neurologia clínica. Ed 5. Porto Alegre, ARTMED, 2005, 472p.

16. HAMID O: Emerging treatments in oncology: focus on tyrosine kinase (erbB) receptor inhibitors. J Am Pharm Assoc 44(1):52-8, 2004.

17. HANNON GJ: RNA interference. Nature 418(6894):244$51,2002$.

18. HILTON DA, MELLING C: Genetic markers in the assessment of intrinsic brain tumors. Curr Diagn Pathol 10:83-92, 2004.

19. IRONSIDE JW, MOSS T, LOWE J, WELLER R, LOUIS DN: Diagnostic pathology of nervous system tumours. London, Churchill Livingstone, 2002. 752p.
20. JUSTINO PB, VILLAR RC, CARVALHO HA, NADALIN W, WELTMAN E: Radiocirurgia e radioterapia estereotáxica: princípios e aplicações. Arq Bras Neurocir 23(4):163-70, 2004.

21. KLEIHUES P, OHGAKI H: Primary and secondary glioblastomas: from concept to clinical diagnosis. Neuro-oncol 1(1):44-51, 1999.

22. KLEIHUES P, CAVENEE WK: World Health Organization classification of tumours: pathology and genetics of tumours of the central nervous system. Lyon, IARC Press, 2000, 314p.

23. KLEIHUES P, LOUIS DN, SCHEITHAUER BW, RORKE LB, REIFENBERGER G, BURGER PC, CAVENEE WK: The WHO classification of tumours of the nervous system. J Neuropathol Exp Neurol 61(3):215-25, 2002.

24. KORSHUNOVA, GOLANOV A, SYCHEVAR. Immunohistochemical markers for prognosis of anaplastic astrocytomas. J Neuro-Oncol 58:203-15, 2002.

25. LANTOS PL, ROSENBLUM MK, KLEIHUES P: Tumours of the nervous system. In Graham PI, Lantos PL (ed): Greenfield's Neuropathology. Ed 7. London, Arnold Publishers, 2002, vol 2, cap 11, pp 583-879.

26. LIUY, NG K, LILLEHEI KO: Cell-mediated immunotherapy: a new approach to the treatment of malignant gliomas. Cancer Control 10(2): 138-147, 2003.

27. LOUIS DN, GUSELLA JF: A tiger behind many doors: multiple genetic pathways to malignant gliomas. Trends Genet 11(10):412-5, 1995

28. LOUIS DN: A molecular genetic model of astrocytoma histopathology. Brain Pathol 7:755-64, 1997.

29. LOUIS DN, CAVENEE WK, LEVIN VA: Neoplasms of the central nervous system. In Devita Jr VT, Hellman S, Rosenberg S: Cancer: principles and practice of oncology. Ed 7. Philadelphia, Lippincott-Williams \& Wilkins, 2005, cap 39, pp 2022-32.

30. LOUIS DN, POMEROY SL, CAIRNCROSS JG: Focus on central nervous system neoplasia. Cancer Cell 1:125-8, 2002.

31. LOURO ID, LLERENA-JUNIOR JC, VIEIRA DE MELO MS, ASTHON-PROLLAP, CONFORTI-FRÓES N (ed): Genética molecular do câncer. Ed 2. São Paulo, MSG Produção Editorial, 2002, 275p.

32. MARIANI SM: Cancer and the immune response: improving the odds. Highlights from the $90^{\text {th }}$ Meeting of the American Association of Immunologists; May 6-10, 2003; Denver, Colorado. MedGenMed 5(2): article 457158, 2003.

33. MENDELSOHN J, BASELGA J: The EGF receptor family as targets for cancer therapy. Oncogene 19:6550-65, 2000.

34. NWOKEDI EC, DIBIASE SJ, JABBOUR S, HERMAN J, AMIN P, CHIN LS: Gamma knife stereotactic radiosurgery for patients with glioblastoma multiforme. Neurosurgery 50(1):41-6; discussion 46-7, 2002.

35. SCHOTTENFELD D, BEEBE-DIMMER JL: Advances in cancer epidemiology: understanding causal mechanisms and the evidence for implementing interventions. Annu Rev Public Health 26:37-60, 2005.

36. SEBTI SM: Blocked pathways: FTIs shut down oncogene signals. The Oncologist 8(suppl 3):30-8, 2003.

37. SHAPIRO GI: Preclinical and clinical development of the cyclin-dependent kinase inhibitor flavopiridol. Clin Cancer Res 10(12/2):4270s-5s, 2004.

38. STEAB, FALSEY R, KISLIN K et al.: Time and dose-dependent radiosensitization of the glioblastoma multiforme $\mathrm{U} 251$ cells by the EGF receptor tyrosine kinase inhibitor ZD1839 ('Iressa'). Cancer Lett 202(1):43-51, 2003.

39. STUPP R, REGG C: New drugs and combinations for malignant glioma. Forum (Genova) 13(1):61-75, 2003.

40. TAILLIBERT S, PEDRETTI M, SANSON M: Current classification of gliomas. Presse Med 33(18):1274-7, 2004. 
41. THIESING JT, OHNO-JONES S, KOLIBABA KS, DRUKER BJ: Efficacy of STI571, an abl tyrosine kinase inhibitor, in conjunction with other antileukemic agents against bcr-ablpositive cells. Blood 96(9):3195-9, 2000.

42. TORSTEN P, WIESTLER OD: Molecular neuropathology of astrocytic brain tumor. J Neuro-Oncol 35:211-22, 1997.

43. TREMONT-LUKATS IW, GILBERT MR: Advances in molecular therapies in patients with brain tumors. Cancer Control 10(2):125-37, 2003

44. VINTERS HV, FARREL MA, MISCHEL PS, ANDERS KH: Diagnostic neuropathology. Boston, Marcel Decker, 1998, 688p

45. VIRCHOW R: Die krankhaften geschwülste. Berlin, Hirshwald, 1863, 496p.
46. ZALUTSKY MR: Targeted radiotherapy of brain tumours. $\mathrm{Br}$ J Cancer 90(8):1469-73, 2004.

\section{Endereço para correspondência:}

Dr. Mário Henrique Girão Faria

Laboratório de Genética Molecular - LABGEM (DPML/UFC)

Av. Benjamim Brasil, 1080 4/102, Mondumbim

60.712-000 - Fortaleza, CE

E-mail:mariofaria@doctor.com 